\title{
Correction to: Modeling, monitoring and forecasting of drought in south and southwestern Iran, Iran
}

\author{
Behroz Sobhani $^{1} \cdot$ Vahid Safarian Zengir $^{1}$
}

Published online: 29 August 2020

(c) Springer Nature Switzerland AG 2020

\section{Correction to: Modeling Earth Systems and Environment (2020) 6:63-71 \\ https://doi.org/10.1007/s40808-019-00655-2}

In the original version of this article, unfortunately a reference has been published incorrectly.

Previously read as

Zolfaghari H, NouriZamara Z (2016) Application of Drought Index (CPEL) in determining proper variables for drought analysis in Iran. J Spat Anal Environ Hazards 3(3):99-114 (in Persian)

It should read:
Zolfaghari H, Noorisameleh Z (2016) Determination of Suitable Variables for Analysis of Droughts in Iran by Using CPEI Index. J Spat Anal Environ Hazards 3(3):99-114.

Publisher's Note Springer Nature remains neutral with regard to jurisdictional claims in published maps and institutional affiliations.

The original article can be found online at https://doi.org/10.1007/ s40808-019-00655-2.

Vahid Safarian Zengir

Safariyan.vahid@gmail.com

1 Department of Physical Geography, Climatology, Faculty of Literature and Humanities, University of Mohaghegh Ardabili, Ardabil, Iran 